\title{
Discussion about the Skills and Methods of College English Teaching from the Pragmatic Point of View
}

\author{
Yuanli Fan \\ School of Foreign Studies, Xi'an University
}

Keywords: Pragmatics; College English; Translation skills; Translation methods

\begin{abstract}
Rapid economic development in the 21 st century, at the same time, our level of education has also been greatly improved. In such a situation the needs of our various aspects of teaching methods and teaching skills to have a great improvement, The college English translation teaching is a good example, at present, our country most of the current number of college English majors curriculum offered professional translation courses mostly only two. For other professional students, courses in this field is even less. In addition, because the university's English Translation Textbooks updates slow, outdated teaching materials, lack of practicality and other reasons, the actual teaching is often difficult to mobilize the students' interest in learning.

The following is a summary of improvement of the problem in terms of pragmatic perspective.

The teaching requirements of college English translation course is very different with the English teaching objectives of high school and even junior school, The university's translation course focuses more on cultivating students' speaking ability and is more in line with standard English translation rules and word order. However, due to various universities for English translation teaching progress and requirements of the difference, teachers focus theirs attention on the basis of teaching for English, That is, in the so-called listening, speaking, reading and writing, ignoring the importance of English translation, so that they can't pass the standard English to students, let them feel English charm. To master English translation skills, is the real starting from the reality of English teaching, is also under the perspective of pragmatics English translation teaching must complete a goal.
\end{abstract}

\section{The Present Situation of College English Translation Course}

Single Teaching Form, Old Translation Content. The current teaching form of college English translation teaching or follow the way of indoctrination classes, teaching schedule cannot be adjusted according to each student's learning characteristics and knowledge to master the situation. Not only that, due to the slow update of college English textbooks, many of the English textbooks are too old, that can't meet the needs of the current social development. As a qualified college students, has been fully equipped self-learning ability, but the vast majority of English teachers, or will choose to spend a lot of time to teaching the basics of English. In fact, for university translation teaching, as long as teach them necessary translation skills, so that they grasp how to accurately translate the meaning of the original in the different scenarios. And then encouraging them to self-study, the teacher side guidance, as long as the teacher guide in place, they are still willing to go to the English translation of the content into energy.

Lack of Innovative Teaching Philosophy. At this stage of university translation teaching, teachers usually give students a large section of text materials for students to analyze, this approach will make a large part of the students do not know how to start. Or in the time of translation and interpretation, although English material can be analyzed, but the analysis like this just to stay in the grammar point of view, very lack of practicality. In this process the teacher's concern is only English itself, rather than the English into Chinese this process. In the long time, this teaching philosophy will make students lack of the coherence between English and Chinese thinking, do not know how to use translation theory, so that students translate the translation is often only a virtual table. Let the teacher translation teaching more targeted, so that students will be able to recognize their own shortcomings. 
The Students' English Communicative Consciousness Is Weak. Learning the language that ultimately are to be attributed to the use of, translation itself is a kind of language communication behavior. The differences between the two cultures make it possible for the students to grasp the translation process from a macro perspective to truly improve the translation process. In this process, students need to cultivate the sense of English communication, let them use a different perspective to look at the differences between the two cultures, so that they can really translate the fluent translation. But the current college students, is very lacking in communication consciousness. Some students would rather indulge in the game than open the hearts to people around. How to learn English well with such a mentality.

\section{Pragmatic Perspective of College Students' Basic Overview of the Translation Theory and Skills}

Language Behavior Theory and Translation Skills. Language behavior theory was put forward by the British philosopher Austin, He believes that the process between people rely on language to communicate mainly divided into three parts: "Metaphors with things", "Doing things with words", "words to succeed". The first part is to understand the content of the discourse and express it. The second part is about the speaker to put his feelings into discourse, which can help listeners to better understand the speaker's intentions. The last "words to succeed," said the listener is to have an impact on their behavior after receiving word. According to the language behavior theory, According to the theory of language and behavior, we can see that the English-Chinese translation is not a simple conversion of the two languages, but an accurate expression of the meaning of English on the basis of accurate information and use of the premise. "Would you like do me a favor .- Coffee, please." These two words, for example, A literal translation of the previous sentence is no problem, but the latter sentence should be based on the specific use of this sentence to conduct accurate translation of the scene. If the place where the conversation takes place in the restaurant, After the sentence should be translated as "I want a cup of coffee." But if the place of the conversation happens in the supermarket, it should be translated "I want to buy coffee." In fact, this simple sentence different responses under different scenarios would just reflect the pragmatic theory of meaning, which also illustrates the importance of culture from a pragmatic perspective students translation skills.

Contextual Analysis and Translation Teaching. Context is simple to understand language environment, language communication process and context are inseparable. And language theory is usually regarded as a part of the context theory, but specifically speaking context not only includes the use of language, but also to ensure that the conversation background knowledge and the degree of mutual understanding between the two sides. From the perspective of English teaching, the context in which the role is also very important. The process of translation is based on the theoretical basis of the text, but the essence of translation should also be on the context of teaching, this should be as an another focus to improve college English translation teaching. To strengthen the students' ability of contextual analysis, they will naturally grasp how to proceed in English translation under different scenarios. To complete this goal, in addition to the teaching in class, also should be in the form of class organization communication activities, creating an opportunity to exercise their ability.

Intercultural Communication and Translation Teaching. In fact, we can be language as a bridge between different cultures, and culture is more like a concentrated expression of language charm. When translation teaching, the students should be encouraged to compare the characteristics of the two cultures independently, let them to understand the language habits of the English-speaking countries in a variety of ways, this also avoids the teacher spending a lot of time explain the status of some English slang. And it is able to solve the students' communicative problems of week consciousness. To give the simplest example, between the Chinese people are familiar friends meet often ask, "have you eaten?", But foreigners greet way is simple, Most of the time they only say "Hi". so in the translation "you eat it" is often translated into "Hi" on it, if literal translation of this sentence at this time, there will be a bit nondescript. 


\section{The Common College English Translation Skills under Pragmatic Perspective}

Literal Translation. English literal translation means is on the basis of without prejudice to Chinese linguistic norms, the English literal meaning directly translated into Chinese. So that the meaning after translated won't appear large deviation, but also conform to the language habits of the text, cultural characteristics and so on, convenient for readers to better grasp the exotic culture characteristics, to truly understand English translation skills. For example, "She is always as busy as a bee", directly translated as "she is as busy as a bee, Here "as busy as a bee" to describe the extent of busy, vivid deliver the article meaning want to express, also more in line with the Chinese translation habits, to ensure the literature and art in the translation. Of course, this way of translation is only for a short if long or compound sentences want to adopt this way of translation must first clarify the overall structure of the sentence.

Amplification. So-called amplification is according to the fluctuation of the original structure, logical relation and the expression of language habits and syntactic characteristics, in the translation process to increase the meaning didn't have in the literal content, but according to the known words can reason out translation meaning. English translation, in theory, can add any words, including nouns, verbs, adjectives, etc., but the specific words to be increased due to the circumstances. For example, "What about calling him right away?" Here increased subject and predicate of translation, translated into Chinese is "give him a call immediately, how do you think this matter". "Indeed, the reverse is true" here increased the noun translation, translated into Chinese is "and the actual situation is just the opposite." In addition, need consider amplification from cultural differences, For example, "The blond boy quickly crossed himself", a simple literal translation of the words, "That blonde little boy immediately painted cross in the chest," but we have to combine Western cultural differences, translated as "The blond boy immediately painted cross in the chest, pray God bless." Through the above statements we can see that proper amplification can guarantee the completeness of the translation. So only to better master English translation skills that we can deliver the content and meaning of the English want to deliver.

Omission. In English translation, omission refers to u don't need translate some words of the original text, but the most basic principle is to ensure that the original meaning can't be damaged and missing. In simple terms that omit some of the non-essential words, In general there are several cases of omission: Omit articles, Namely "a, an, the" like these definite articles, for example, "A book is useful" can be translated directly into "this book is useful" rather than highlighting quantifier "a". There is the omission of pronouns, including personal pronouns, possessive pronouns, such as "it". In addition there is an attention to omit category words and repeated words. In Chinese, we often use rhetorical devices to strengthen the tone like parallelism, repeat, but the English expression is more straightforward, so the translation should avoid duplication and remove unnecessary translations.

Conversion. Conversion means one part of words in English is converted to another words when translated into Chinese, Conversion of sentence is unfolded between on subject, predicate, object and so on. For example, in "He is no smoker, but his father is a chain-smoker." The none is translated into verb, namely "He does not smoke, his father is one and a non-stop." And "I am totally a stranger in this city", the noun is translated into adjective, namely "I am completely unfamiliar to the city." The translation requires the students' language skills are high, students can use this translation method flexibly only on the basis of mastering some foundation.

\section{Summary}

Translation itself is the collision of two kinds of cultures, English translation is the flexible conversion and application between English and Chinese, From a pragmatic perspective to learning English translation skills, to be able to accurately realize the cultural features of English, promoting the integration of foreign culture and national culture, better communication and learning in two languages. There are many techniques and methods in English translation, in the process of application also need our flexibility to master, according to language habits and cultural 
characteristics, select the most suitable translation method, only in this way can achieve the best translation results. This article is some of the author's ideas and thinking, the author hopes to give some Suggestions for related personnel, also hope it's helpful to improve the current English translation of the teaching situation.

\section{References}

[1] Chenyi Chen. A written translation ability survey of the undergraduates in English Translation Studies. [D]. Henan Normal University, 2012.

[2] Shouhong Wang. A research of translation strategies of foreign publicity from the perspective of Cross-cultural pragmatics [D]. Shanghai International Studies University, 2012.

[3] Guiqin Chen. The problems and countermeasures of College English cross-cultural teaching [D]. Shanghai International Studies University, 2014.

[4] Yanfei Du. A research of Pragmatic Adaptation Theory in College English Translation Teaching Application - A Case Study of Baicheng Normal University [J]. Baicheng Normal University, 2016, 06: 40-42 + 52 .

[5] Qianqian Wang. A typical error analysis in English major undergraduate translation practice [D]. Yangtze University, 2013.

[6] Jianling Zou. Retrospect and Prospect of Tourism Translation Studies in the Past 15 Years based on Core Journals analysis in 1998-2012 [A] A new progress in scientific translation [C]., 2015: 8 . 